\title{
A MEDIAÇÃ̃ DA PSICOLOGIA DA EDUCAÇÃO EM PROCESSOS FORMATIVOS: UMA EXPERIÊNCIA COM A FORMAÇÃO DE PROFESSORES
}

\author{
PENTEADO, Maria Emiliana Lima'; SIGALLA, Luciana Andréa Afonso² .
}

\section{RESUMO}

Este artigo tem como objetivo apresentar parte de um processo formativo que teve como temática o trabalho com diferentes gêneros discursivos na sala de aula e utilizou-se de uma metodologia autoral inspirada na Psicologia Sócio-Histórica de Vigotski e seus seguidores. A formação contou com a participação de 60 professores de Ensino Fundamental - Anos Iniciais - e seus coordenadores, de uma rede pública municipal paulista. Dentre outros achados, o referido processo revelou que ter um momento de reflexão no qual pudessem expressar suas significações acerca do que é ser professor foi algo muito importante para os participantes, razão pela qual defende-se, neste trabalho, a necessidade de se repensar a formação continuada de professores, lançando um olhar para além dos conteúdos que esses profissionais certamente precisam dominar.

Palavras-chave: Formação continuada de professores. Estratégias de formação docente. Espaços reflexivos de formação.

\begin{abstract}
This article aims to present part of a formative process that had as its theme the work with different discursive genres in the classroom; it used an authorial methodology inspired by Vigotski's Socio-Historical Psychology and his followers. The formation course was attended by 60 elementary school teachers - Early Years and their coordinators from a public municipal system in São Paulo municipality. Among other findings, the aforementioned process revealed that having a moment of reflection in which they could express their meanings about what is being a teacher was something very important for the participants; therefore, this paper seeks to defend the need to rethink the continuing teacher formation, glancing beyond the content that these professionals must surely dominate.
\end{abstract}

Key words: Continuing teachers' formation. Teacher formation strategies. Reflective spaces of formation.

\footnotetext{
${ }^{1}$ Doutora e Mestra em Educação: Psicologia da Educação, pela Pontifícia Universidade Católica de São Paulo (PUC-SP). Coordenadora pedagógica da Secretaria Municipal de Educação de São Paulo. Docente nas Faculdades Integradas Campos Salles e docente convidada nas Faculdades Integradas Rio Branco. Pesquisadora do Grupo Atividade Docente e Subjetividade da PUC-SP. E-mail: emipenteado@gmail.com.

${ }^{2}$ Doutora e Mestra em Educação: Psicologia da Educação, pela Pontifícia Universidade Católica de São Paulo (PUC-SP). Atualmente, é docente convidada das Faculdades Integradas Rio Branco e do Centro Universitário Unifaat. Pesquisadora do grupo de pesquisa Contexto Escolar, Processos Identitários da Formação de Professores e Alunos da Educação Básica (CEPId/CNPq), da PUC-SP. E-mail: luciana.sigalla@gmail.com.
} 


\title{
Introdução e Objetivos
}

Documentos oficiais, como a Lei de Diretrizes e Bases da Educação Nacional (LDBEN) n 9.394/1996 (BRASIL, 1996) e, mais recentemente, o Plano Nacional de Educação (PNE), aprovado pela Lei $\mathrm{n}^{\mathrm{o}}$ 13.005/2014 (BRASIL, 2014), reforçam que a história da educação brasileira aponta para uma preocupação constante com a formação de professores e que tem alcançado avanços significativos nesse campo a partir da criação e da implementação de políticas públicas voltadas para esse fim. Os conteúdos expressos nesses documentos constatam que o professor bem formado é peça fundamental para promover a boa qualidade do processo de ensino e de aprendizagem.

Com relação ao PNE, Penteado (2017, p. 30) aponta que:

\begin{abstract}
O documento promete uma atenção especial ao profissional que está à frente do processo ensino-aprendizagem. Podemos pontuar isso como um avanço das políticas públicas no âmbito da formação docente, mas há uma questão a ser clarificada: os docentes estão satisfeitos com as formações que lhes estão sendo oferecidas? Como se dá a participação desses profissionais nas situações formativas? Como pensam os professores sobre "ser professor" e sua atividade, a docência? Essas questões são consideradas na formulação e no desenvolvimento dos processos formativos?
\end{abstract}

A formação de professores é, portanto, um assunto em evidência no Brasil, em especial, a formação continuada, alvo de pesquisas científicas que partem de diferentes perspectivas teóricas, para sua melhor compreensão e seu aprimoramento.

Segundo Placco (2008, p. 192), a formação continuada "deve ser entendida como um processo que ocorre a partir da formação inicial e se estende para além de cursos e treinamentos, sendo provocadora de inquietação contínua com o já conhecido.”

Entende-se, pois, que a formação continuada de professores deva ir além da simples atualização de conhecimentos relativos à área de atuação do professor. Mais do que isso, conforme aponta Vasconcellos (2003, p. 147), ela deve propiciar espaços de reflexão crítica, coletiva e constante sobre a prática, essenciais "para um trabalho que se quer transformar, na medida em que possibilita a unidade entre o sujeito da ação e da reflexão".

Diante do exposto, o objetivo deste trabalho é apresentar parte de um processo formativo que teve como temática o trabalho com diferentes gêneros discursivos na sala de au la e utilizouse de uma metodologia autoral inspirada na Psicologia Sócio-Histórica. 


\section{Referencial Teórico}

A Psicologia da Educação é uma área do conhecimento científico que se ocupa da dimensão psicológica do processo de ensino e de aprendizagem, com ênfase nas questões de aprendizagem e desenvolvimento humano, que busca iluminar, por meio de seu arcabouço teórico, a relação que se constitui nesse complexo processo e fortalecer a autonomia dos envolvidos.

Nesse sentido, a Psicologia da Educação poderá contribuir com os fazeres pedagógicos, por meio de análises contundentes dos fenômenos educacionais, à luz de diferentes concepções acerca da aprendizagem e do desenvolvimento humano na história, na sociedade e na cultura. Esse modo de compreender a Psicologia da Educação está em consonância com as ideias de Gatti (2019, p. 45), que a define como uma área de conhecimento multifacetada, dinâmica e mutante, constituída "nos movimentos histórico-culturais e científicos".

Sediada no campo da Psicologia da Educação, encontra-se a perspectiva da Psicologia Sócio-Histórica, que iluminou o processo formativo apresentado neste artigo e que está ancorada em Vigotski e seus seguidores, que buscavam possibilidades de explicar os fenômenos da realidade de modo dialético, sem dicotomizá-los, assumindo, assim, uma visão crítica e totalizante.

Nessa linha de pensamento, Bock (2011, p. 17) afirma que a "Psicologia Sócio-Histórica carrega consigo a possibilidade de crítica. Não apenas por uma intencionalidade de quem a produz, mas por seus fundamentos epistemológicos e teóricos”. A Psicologia Sócio-Histórica fundamenta-se no método do Materialismo Histórico e Dialético, compreendendo, desse modo, o ser humano como sujeito histórico, atuante numa sociedade que o constitui e que é constituída por ele.

\section{Metodologia}

Conforme mencionado, o objetivo deste trabalho é apresentar parte de um processo formativo que teve como temática o trabalho com diferentes gêneros discursivos na sala de aula e utilizou-se de uma metodologia autoral inspirada na Psicologia Sócio-Histórica.

A proposta geral do referido processo formativo foi expandir o conhecimento dos professores de Ensino Fundamental - Anos Iniciais -, de uma rede pública municipal paulista, sobre a função social dos variados gêneros discursivos veiculados na sociedade, a partir da 
reflexão, da experimentação e da compreensão de por que e como esses gêneros vêm sendo ensinados e aprendidos na escola.

A formação foi realizada nas dependências da secretaria municipal de educação, em parceria com uma instituição de ensino superior particular, e contou com a participação de, aproximadamente, 60 professores e seus coordenadores. Com o objetivo de propiciar uma formação que atendesse às necessidades dos diferentes ciclos, os participantes foram distribuídos em duas turmas (turma 1: $1^{\mathrm{os}}, 2^{\mathrm{os}}$ e $3^{\mathrm{os}}$ anos; turma 2: $4^{\mathrm{os}}$ e $5^{\mathrm{os}}$ anos), cada qual com sua respectiva formadora ${ }^{3}$, que acompanhou sua turma do início ao final do processo. No total, foram realizados seis encontros, com três horas de duração cada, totalizando 18 horas de formação.

O processo formativo ora apresentado teve como objetivo central promover condições de análise de situações de ensino e de aprendizagem, no que se refere ao trabalho com gêneros discursivos como parte integrante do processo de alfabetização e letramento.

Constituíram-se objetivos específicos:

- Discutir questões teóricas e práticas relacionadas ao processo de alfabetização e letramento, à luz dos referenciais teóricos atuais existentes na área e do material didático adotado pela rede municipal de ensino.

- Evidenciar os referenciais teóricos e metodológicos da alfabetização e do letramento, a partir de sua perspectiva histórica e, desse modo, dialogar com o material didático utilizado.

- Discutir e refletir sobre a organização do trabalho pedagógico em sala de aula e sua relação com o trabalho com gêneros discursivos no processo de alfabetização e letramento, a partir da visão do aluno real e do seu direito de aprendizagem.

- Refletir e colocar em debate situações práticas da sala de aula, buscando analisá-las coletivamente e compreendê-las a partir das discussões realizadas.

- Socializar atividades desenvolvidas pelos professores em sala de aula, consideradas por eles bons exemplos de práticas de alfabetização e letramento com o uso dos gêneros discursivos.

Os encontros contaram com momentos propiciadores de articulação teórico-prática, evidenciando a não dicotomia desse par dialético, em que cada um - teoria e prática -, ao mesmo tempo em que mantém sua especificidade, não é sem o outro, pois ambos constituem

\footnotetext{
${ }^{3}$ As formadoras aqui mencionadas são as autoras deste artigo.

Momentum, Atibaia, v. 1, n. 17, p. 1-12, 2019.
} 
uma unidade de contrários. Desse modo, ousa-se promover um movimento rumo à práxis, em consonância com o pensamento de Vázquez (2007, p. 259), que aponta que "a prática não fala por si mesma e exige, por sua vez, uma relação teórica com ela: a compreensão da práxis".

Visando à clareza e a uma melhor organização do trabalho, a cada encontro, as formadoras projetavam aos participantes slides (PPT) de retomada dos tópicos do encontro anterior e do que seria discutido no dia. Quando necessário, o último slide trazia orientações para o(s) próximo(s) encontro(s), como, por exemplo, ler/estudar algum texto ou trazer o material didático utilizado em sala, com os alunos.

A todo momento, buscou-se valorizar o que os participantes já sabiam, estimular sua criatividade, favorecer o pensamento crítico em relação ao material didático utilizado na rede e aprofundar o conhecimento do conteúdo específico da formação.

A seguir, apresenta-se parte do processo formativo realizado com os professores e coordenadores, referente ao primeiro encontro ${ }^{4}$, bem como sua análise e seu desdobramento, que culminou em uma surpresa para os participantes no último encontro, encerrando, assim, o processo formativo proposto.

\section{Análise e Discussão dos Dados}

O objetivo do primeiro encontro foi conhecer os participantes, aproximar-se deles e saber de suas expectativas de formação. Para isso, propôs-se uma vivência inspirada nos trabalhos realizados pela Profa. Dra. Ana Mercês Bahia Bock ${ }^{5}$ e seu grupo de pesquisa, que consiste em propor situações de diálogo dos participantes com um alienígena (ET). Espera-se que o alienígena, aquele que nada sabe sobre o tema a ser proposto, ao fazer perguntas, consiga provocar, naquele que responde, um movimento de pensar sobre o seu pensar, ao tentar explicar algo, de maneira mais detalhada, a alguém que nada sabe sobre o que vai ser explicado. Nesse processo de pensar o que e como vai explicar algo totalmente desconhecido para o outro, o participante elabora diferentes estratégias para expressar o que sabe sobre determinado assunto e, desse modo, poderá revelar o que pensa, o que sente e quais são suas ações no mundo.

No caso do processo formativo em tela, criou-se uma situação de diálogo entre duas personagens, especificamente um professor e um alienígena, conforme propõe Penteado (2017), a fim de favorecer a objetivação das significações (AGUIAR; OZELLA, 2006, 2013) dos

\footnotetext{
${ }^{4}$ Por uma questão de foco, os demais encontros formativos não serão tratados neste trabalho.

${ }^{5}$ Psicóloga e docente do Programa de Estudos Pós-Graduados em Educação: Psicologia da Educação, da PUC-SP. Momentum, Atibaia, v. 1, n. 17, p. 1-12, 2019.
} 
participantes sobre estas questões: (1) O que é "professor"? (2) O que você fez para ser professor? e (3) O que você está fazendo aqui, agora?

Para tanto, a vivência foi realizada em três momentos, explicitados a seguir.

\section{Primeiro momento: dando vida às personagens...}

Neste primeiro momento, cada turma, em sua respectiva sala, foi dividida em dois pequenos grupos. Como parte da estratégia formativa, os grupos não deveriam saber o que o outro estava fazendo, por isso um grupo permaneceu na sala de origem e o outro foi levado para uma sala próxima.

Em seguida, solicitou-se que cada grupo fizesse um desenho específico. Ao grupo que permaneceu na sala de origem, solicitou-se o desenho de um professor. Ao outro grupo, o desenho de um alienígena (ET). Para a realização dos desenhos, cada grupo recebeu uma folha de papel craft $(1,80 \mathrm{~m} \times 80 \mathrm{~cm})$, canetinhas hidrocor e gizes de cera, de cores variadas. Além de desenhar as personagens, caracterizando-as, os participantes deveriam nomeá-las e criar uma história de vida para elas.

Finalizado o trabalho, o segundo grupo retornou à sala de origem e, com a turma toda reunida, foi proposto que cada grupo afixasse o desenho de sua personagem no quadro de giz e a apresentasse a todos, contando-lhes quem era a personagem, qual seu nome e qual sua história de vida.

\section{Segundo momento: estabelecendo o diálogo...}

Em um segundo momento, após a apresentação das personagens, colocou-se a seguinte situação aos participantes:

Imaginem que este professor (personagem criada pelo primeiro grupo) estivesse aqui conosco e saísse, por alguns instantes, para fazer uma ligação telefônica a alguém. Ao sair desta sala, ele se depara com o ET(personagem criada pelo segundo grupo) e ambos começam uma conversa, durante a qual, o professor diz ao ET que é professor, e o ET, então, faz a ele as seguintes perguntas:

1. O que é "professor"?

2. Como você fez para ser professor?

3. O que você está fazendo aqui, agora? 
Após a exposição dessa situação, solicitou-se aos participantes que, individualmente, respondessem às perguntas feitas pelo ET ao professor e que entregassem suas respostas à formadora.

\section{Terceiro momento: nós e o ET...}

Após a entrega das respostas à formadora, solicitou-se aos participantes que, em grupos de três ou quatro pessoas, elaborassem uma síntese de suas respostas individuais para apresentála à turma.

Na sequência, cada trio ou quarteto apresentou sua síntese, colando-a, em seguida, no desenho do ET, que permanecia afixado no quadro de giz, ao lado do desenho do professor.

Para finalizar, propôs-se aos participantes uma conversa sobre os objetivos da vivência: para eles, qual seria o propósito de cada pergunta feita pelo ET?

Ao refletirem e discutirem sobre isso, os participantes perceberam que as perguntas tinham como propósitos, respectivamente:

1. Identificar os significados que eles, participantes, atribuíam à sua profissão (1. O que é "professor"?).

2. Aproximar-se dos sentidos atribuídos por eles à sua atividade profissional (2. Como você fez para ser professor?). Ao explicar isso, não havia como não contarem sua história, não falarem sobre si.

3. Identificar suas expectativas com relação à formação (3. O que você está fazendo aqui, agora?).

Assim, o processo formativo transcorreu, propiciando aos participantes, a cada encontro, vivências e discussões pertinentes aos objetivos propostos pelas formadoras, até que se chegasse ao sexto e último encontro, que, dentre as atividades realizadas, culminou com a avaliação do processo.

Nesse dia, quando menos esperavam, os participantes foram surpreendidos com uma carta que a formadora "recebeu" do ET, para que fosse entregue a eles.

A carta, lida em voz alta pela formadora, dizia o seguinte:

Bellatrix, Constelação de Órion, [data].

Queridas(os) professoras(es) de [nome da cidade], 
É com grande satisfação que escrevo esta carta.

Primeiramente, quero agradecer a vocês por terem me recepcionado no planeta Terra, especificamente em [nome da cidade], e terem respondido às minhas perguntas, feitas a partir do meu interesse sobre o que é ser professor. Sinto-me muito grato por isso!

Eu sei como o tempo do planeta de vocês está ficando pequeno. Nele, parece não caber a quantidade de atividades criadas para atender às necessidades humanas, não é mesmo? Percebi muitas coisas interessantes nos dias em que estive por aí...

Agora, com a colaboração de vocês, além de outras coisas, sei um pouco sobre "o que é ser professor", especialmente, o que é ser professor do ensino público em [nome da cidade]. Aqui no meu planeta, as coisas são diferentes, pois é outra realidade. No entanto, entender o que é ser professor em [nome da cidade] ajudou-me a ampliar o meu olhar sobre o que é ser professor em outros planetas, inclusive no meu. Qualquer dia desses, eu retornarei a [nome da cidade] $e$, se vocês tiverem interesse, posso tentar explicar...

Quero ressaltar que considero que ainda tenho muito a aprender sobre o que é ser professor, pois entendi que a realidade humana é muito dinâmica e não admite o conhecimento como algo pronto, acabado e estático. Pelo contrário: o conhecimento é movimento, é processo de transformação que impulsiona a aprendizagem e o desenvolvimento humano.

Assim, até o momento, entendi o seguinte sobre o que vocês explicaram sobre o que é ser professor: para esse grupo de professores da escola pública de [nome da cidade], ser professor é, por natureza, vocação ou formação, um ser humano, um profissional que tem ou adota, como propósito de vida, ensinar e aprender constantemente, seja na ação pedagógica ou fora dela. É uma pessoa com saberes constituídos ao longo da vida e com conhecimentos específicos, adquiridos em diferentes cursos, para ser, cada vez mais, "um bom professor". Aqui, eu fiquei com uma dúvida... Sabe como é, quanto mais a gente aprende, mais dúvidas aparecem... Será que as pessoas "nascem” professores ou "tornam-se” professores? Tenho estudado um pouco essa questão do que é ser professor, pois fiquei muito interessado no assunto e resolvi me aprofundar.

Há um educador do planeta Terra, Paulo Freire, muito admirado aqui em Bellatrix, que diz que ninguém nasce professor num determinado dia e horário, mas que nos constituímos professores ao longo de nossas vidas. É certo que muitos de vocês disseram isso, mas ainda tem muita gente que acredita que é um dom natural. Será? 
Há também um psicólogo do planeta Terra, muito conhecido na área da educação, Lev S. Vigotski, que discute questões bem parecidas, porém com um aprofundamento nas questões psíquicas. Mas vamos deixar essa conversa para outra ocasião...

Os professores de [nome da cidade] disseram também que, para se tornar professor, é necessário dedicar parte de sua vida, de seu tempo, realizando cursos de graduação, pósgraduação e de atualização, como este que, fiquei sabendo, está terminando hoje (espero que cada um, à sua maneira, tenha aproveitado algo, afinal, na vida, estamos sempre aprendendo...).

Vocês responderam também que o professor, em [nome da cidade], é um ser humano que se considera um "mediador" na sala de aula, ou seja, um profissional que reconhece como é importante fazer a interlocução entre o conhecimento científico (professor) e o conhecimento espontâneo, próprio do senso comum (alunos), de diferentes maneiras, atuando em diferentes situações, concretas elou de dimensões preponderantemente subjetivas.

O professor, em [nome da cidade], é alguém que olha para o outro (aluno) como alguém que está prestes a aprender algo novo; alguém que carrega consigo um saber. E o professor é aquele que ensina esse algo novo e que produz situações desafiadoras nas quais os alunos colocam em jogo o que já sabem e o que não sabem sobre o objeto de conhecimento e, desse modo, podem produzir novas aprendizagens e se desenvolver. Aliás, acho que vocês aprenderam isso com aquele psicólogo que citei, não é? Acho que tem a ver com um conceito chamado Zona de Desenvolvimento Proximal (ZDP). Sabia que esse psicólogo era russo e que escrevia seus textos em russo? Língua complicada! Muitas traduções dos seus textos trazem equívocos e, dependendo da interpretação, é bem perigoso... Pensem nisso!

Quero ressaltar que vocês me fizeram pensar o quanto é importante ser professor em [nome da cidade], especialmente na escola pública. Fiquei sabendo da situação política que avassala a educação brasileira e que [nome da cidade] não está apartada desse cenário. Como disse, estou estudando! Aprendi um pouco sobre políticas públicas e sei da importância da luta dos professores para se firmarem na profissão docente como, nas palavras de vocês, "um profissional, um trabalhador”. Essa luta é legítima! E, em qualquer outro lugar, ela não cessa.

A sala de aula é um espaço político. No entanto, a meu ver, diferente da política partidária. Lembrando aquele educador citado, Paulo Freire, a prática pedagógica é uma prática política quando existe engajamento ético e responsabilidade social no processo de ensino-aprendizagem. Diante dessa reflexão, registro aqui mais alguns questionamentos, colocando-me como um professor ET... Que profissionais somos? Que profissionais queremos 
ser? Quais são nossos projetos de vida? Quem são as pessoas que estamos educando ou que pretendemos educar? O que e como estamos ensinando? O que e como nossos alunos estão aprendendo? Que educação queremos para nosso país?

Peço licença para reproduzir, mais uma vez, algumas das respostas dadas por vocês sobre o que é ser professor, para dizer o quanto vocês são fundamentais no processo educativo: "O professor é uma pessoa disposta a ajudar e ensinar o próximo e aprender"; "Um ser que procura sempre o melhor, contribuindo para a formação de um cidadão para o mundo”; "É alguém que ensina e aprende com o outro ser humano"; "É uma profissão gratificante, que todos têm que passar por ela"; "Professor é alguém com quem irá se partilhar, vivenciar, descobrir, divertir...”; “Estudei, corri atrás, cansei, não dormi, chorei, sorri, insisti, não desisti e alcancei”,; "Estudei, ralei durante muitos anos e continuo estudando".

Para finalizar esta carta, dedico a vocês esta mensagem de uma grande poetisa e contista brasileira, que tive o prazer e a alegria de conhecer em Goiás, numa breve passagem pela Terra, há uns 30 anos: Cora Coralina... Diz ela:

"Não sei se a vida é curta ou longa para nós, mas sei que nada do que vivemos tem sentido, se não tocarmos o coração das pessoas.

Muitas vezes basta ser: colo que acolhe, braço que envolve, palavra que conforta, silêncio que respeita, alegria que contagia, lágrima que corre, olhar que acaricia, desejo que sacia, amor que promove.

E isso não é coisa de outro mundo, é o que dá sentido à vida. É o que faz com que ela não seja nem curta, nem longa demais, mas que seja intensa, verdadeira, pura, enquanto durar. Feliz aquele que transfere o que sabe e aprende o que ensina."

E assim me despeço, ansiando pelo dia em que eu possa retornar à Terra, este lindo planeta azul, e, quem sabe, ter o prazer de rever todos vocês.

Um grande abraço,

ET. 


\section{Considerações Finais}

O processo formativo apresentado neste trabalho revelou para as formadoras quanto foi importante para os participantes terem um momento de reflexão no qual pudessem expressar suas significações acerca do que é ser professor. Isso pôde ser percebido não apenas na elaboração das respostas dadas pelos participantes ao ET, na vivência proposta no primeiro encontro, mas durante todo o processo.

Ao escreverem a carta do ET aos participantes e a lerem em voz alta no último encontro, as formadoras puderam dar-lhes uma devolutiva da vivência realizada no primeiro encontro. $\mathrm{Na}$ carta, o ET traz questionamentos que colocam em evidência pontos que precisam ser postos em discussão. Exemplo disso é o momento em que ele aponta para a necessidade de os participantes pensarem no significado da profissão docente, quando questiona seu entendimento como um "dom" e quando ressalta as respostas dos professores sobre "quem é o professor e o que ele faz".

Em outro momento, o ET, ao citar Paulo Freire e Vigotski, chama a atenção dos participantes para a importância de investirem em seu desenvolvimento profissional e de refletirem sobre suas práticas. O ET também coloca em xeque as fragilidades das formações, quando cita o conceito vigotskiano de Zona de Desenvolvimento Proximal (ZDP).

Para concluir, lança-se aqui uma proposição para a realização de processos formativos: é preciso repensar a formação continuada de professores, lançando um olhar para além dos conteúdos que esses profissionais certamente precisam dominar. Entende-se que se faz necessário pensar em processos formativos que visem à formação de seres humanos capazes de olharem para si e de reconhecerem os importantes papéis que exercem na sociedade; processos que, de fato, contribuam para o desenvolvimento profissional docente; processos que, acima de tudo, constituam-se espaços reflexivos capazes de provocar reais transformações na prática pedagógica dos professores.

\section{Referências}

AGUIAR, W. M. J.; OZELLA, S. Apreensão dos sentidos: aprimorando a proposta dos núcleos de significação. Revista Brasileira de Estudos Pedagógicos, Brasília, v. 94, n. 236, p. 299-322, jan./abr. 2013. Disponível em: http://www.scielo.br/pdf/rbeped/v94n236/15.pdf . Acesso em: 20 ago. 2019. 
Núcleos de significação como instrumento para a apreensão da constituição dos sentidos. Psicologia: Ciência e Profissão, São Paulo, v. 26, n. 2, p. 222-247, 2006. Disponível em: http://www.scielo.br/pdf/pcp/v26n2/v26n2a06.pdf . Acesso em: 20 ago. 2019.

BOCK, A. M. B. Fundamentos teóricos da psicologia sócio-histórica. In: BOCK, A. M. B; GONÇALVES, M. G. M.; FURTADO, O. (orgs.). Psicologia sócio-histórica: uma perspectiva crítica em psicologia. 5. ed. São Paulo: Cortez, 2011.

GATTI, B. A. Conversando sobre o campo da psicologia da educação. In: ALMEIDA, L. R.; RONCA, A. C. C. (orgs.) 50 anos de produção em psicologia da educação: relatos de pesquisa. Campinas, SP: Pontes Editores, 2019.

PENTEADO, M. E. L. A dimensão subjetiva da docência: significações de professores e gestores sobre "ser professor", produzidas em um processo de pesquisa e formação. 2017. Tese (Doutorado em Educação: Psicologia da Educação) - Pontifícia Universidade Católica de São Paulo - PUC-SP, São Paulo, 2017. Disponível em:

https://tede2.pucsp.br/handle/handle/20566 . Acesso em: 28 ago. 2019.

PLACCO, V. M. N. de S. Processos multidimensionais na formação de professores. In: ARAÚJO, M. I. O.; OLIVEIRA, L. E. (orgs.). Desafios da formação de professores para o século XXI: o que deve ser ensinado? O que é aprendido? Universidade Federal de Sergipe, CESAD, 2008, p. 185-198.

VASCONCELLOS, C. S. Para onde vai o professor? Resgate do professor como sujeito de transformação. 10. ed. São Paulo: Libertad, 2003. (Col. Subsídios Pedagógicos do Libertad, v. $1)$.

VÁZQUEZ, A. S. Filosofia da práxis. São Paulo: Expressão Popular, 2011. 